Article

\title{
The Arts of Energy: Between Hoping for the Stars and Despairing in the Detritus
}

\author{
Josh Wodak
}

Faculty of Art \& Design, University of New South Wales, Sydney NSW 2021, Australia; j.wodak@unsw.edu.au; Tel.: +61-(2)-8936-0803

Academic Editor: Adam Sweeting

Received: 27 December 2015; Accepted: 13 May 2016; Published: 3 June 2016

\begin{abstract}
Fossil fueled energy production and consumption are the basis of global industrialised societies, with the deleterious biophysical effects of such production and consumption also forming the basis of the advent of Anthropocene. In the context of science and environmental policy, hope denotes rapid decarbonisation across the globe. Meanwhile, in art and the humanities, the study of such energy and decarbonisation remains nascent and nebulous. To account for these discrepancies, this article outlines the scale of the biophysical challenges by first establishing the relationship between outspoken climate scientists and international organisations determining climate and energy policy. This relationship — between marginalised and mainstream-is used to frame the analogous challenges for two cultural fields that have recently emerged in direct response: energy humanities and the arts of energy. The discussion centers on the challenge common to all fields-between the outspoken marginal and the orthodox mainstream - to speculate on how the arts of energy may recalibrate a context-contingent hope for energy futures, drawing on case studies of ISEA Bright Future and Facing Futures Free From Fear, two installations simultaneously staged by the author in 2013 about the relationship between energy and climate change.
\end{abstract}

Keywords: energy; energy humanities; renewable energy; fossil fuels; climate change; Anthropocene; art; climatology; space exploration

\section{Emperors, Elephants, and Energy}

It is 6 November 2012 at the University of Bristol. The Cabot Institute, the University's cross-disciplinary research institute for 21st century environmental challenges, is holding its annual lecture as part of the University's Festival of Social Sciences and Law. The auditorium is filled to capacity, there to hear from Professor Kevin Anderson, one of the world's leading climate scientists. A chartered engineer initially trained in mechanical engineering, Anderson has since strayed outside of engineering, having been Director of the UK's Tyndall Centre for Climate Change Research, one of the foremost climate change research institutes in the world, of which he is presently Deputy Director. He has also purposefully strayed outside of climate science and into the relationship between climate change and the politics and policy of energy, as Professor of Energy and Climate Change in the School of Mechanical, Aeronautical and Civil Engineering at the University of Manchester. His straying outside of domains and disciplines extends beyond the normative role played by scientists and academics and into the activism of working in and against UK government commissions around climate and energy policy. This level of eclecticism appears to have fuelled the capacity interest in his lecture. 
All these knowledge strands and traversed disciplinary boundaries are held together by something of a different order all together: the cultural trope of a fairy tale by Hans Christian Andersen ${ }^{1}$. The title of Anderson's lecture illustrates this fluid movement between the humanities and the sciences: "Real Clothes for the Emperor: Facing the Challenges of Climate Change." He walks into the room, and opens with a provocation:

I think the Emperor's streaking in front of us naked while most of us are saying "aren't they beautifully attired", including many scientists. I think actually if you stand up and say that the Climate Change Emperor is naked most people will shut you down. They do not want to hear that, however obvious it may be ([1], p. 1).

Hans Christian's fable about The Emperor's New Clothes [2] offers an instantly recognisable analogy for the elephant in the room: the chasm between the rhetoric espoused by central climate change organisations such as the Intergovernmental Panel on Climate Change (IPCC) and the United Nations Framework Convention on Climate Change (UNFCCC) and what Anderson maintains is reality. The rhetoric concerns the efficacy of global attempts to limit anthropogenic climate change to $2^{\circ}$ mean surface temperature increase above pre-industrial levels by 2100 , versus the contested extent of the catastrophic consequences of such a $2^{\circ}$ rise, versus the reality of the overwhelming probability of increases being order of magnitude more than $2^{\circ}$.

Over the following hour, Anderson reveals the extent of this chasm between rhetoric and reality, detailing historical and contemporary graphs, statistics and data of global deleterious biophysical change from fossil fuelled energy emissions, and of the rapidly narrowing possibility for restricting climate change to a $2^{\circ}$ increase, arguing that organisations such as the IPCC and UNFCCC are significantly downplaying the extent to which the current trajectory is toward a $6^{\circ}$ increase by 2100 [3]. The difference between these trajectories boils down to the threshold of $2^{\circ}$, where increases of less or more than $2^{\circ}$ are understood to be the main tolerance threshold for the biophysical systems which support life to continue functioning anything like they did in the Holocene, the unseasonably benign era since civilisation emerged from its cradle.

Anderson is representative of a small minority of scientists who are both internationally renowned, but also avowedly outspoken in detailing the extent of this chasm. He invokes Hans Christian's fable in relation to his risk as the marginalised laying bare the mainstream, including the relationship between outspoken climate scientists and the orthodoxy represented by the IPCC and UNFCCC. While The Emperor's New Clothes offers a common cultural reference point, the idiom of the elephant in the room is more apt in relation to the risk at hand. Hans Christian's fable of a foppish Emperor striding naked down the street speaks eloquently of the relationship between the marginal and the mainstream regarding art, aesthetics and power, yet the fable lacks the portent inherent to anthropogenic climate change. A naked elephant in the room serves as a more apposite metaphor for the inherent sensitivity, unpredictability and volatility of the climate system, which the similarly outspoken climate scientist Wallace Broecker describes as "an angry beast" with anthropogenic forcing constituting "poking it with sticks" [4]. To declare the existence of the elephant is a further risk from acknowledging the collectively denied existence of collective denial, as described by Eviatar Zerubavel in his polemic The Elephant in the Room: Silence and Denial in Everyday Life [5].

In the context of climate change, to declare this existence is also to acknowledge the risk of being in a room with an elephant driven to anger at being poked by sticks. That is, the combined anthropogenic driving of these global challenges have exerted such extensive influences on Earth Systems that the cumulative geomorphic force has shifted Earth out of the Holocene, the prior geological era, and into the Anthropocene: a new geological era defined by homo sapiens as the dominant influence on Earth Systems [6]. As a metaphor, the elephant has already been driven to anger by being poked by sticks.

1 Hans Christian Andersen is subsequently referred to as "Hans Christian" to distinguish him from Kevin Anderson. 
In actuality, the species has also become critically endangered, and is being driven towards extinction when factoring in the inexorable global challenges facing the biosphere.

Anderson's work aims to precipitate the community-wide "ah ha!" realisation of the child who first openly acknowledges Hans Christian's Emperor is naked, so that it occurs at the critical point before the Emperor would have completed the parade and returned to his royal fortress. Anderson employs the timing of this critical realisation in the fable to his analogous experience participating in international energy policy negotiations, where there is a finite time to close the gap between rhetoric and reality through a global-community-wide "ah ha!" realisation that precipitates the enactment and enforcement of energy policy reform. His polemic is informed by a critical stance toward techno-scientific "fixes" as a means to lessen the discrepancy between biophysical and anthropocentric deadlines. To relate this back to the metaphor-actuality of the elephant in the room: there is even an elephant of a different order all together: slated to give birth to a wooly mammoth resurrected via "de-extinction" [7] through synthetic biology, genetic engineering and cloning [8]. Such proposals are analogous to energy emissions negotiations wherein a biophysical tipping point can be crossed, like a species going extinct, save for a techno-scientific "Undo" keyboard command further down the track of time.

The chasm between climate change rhetoric and reality is the subject of debate between political and politicised rhetoric from major scientific, governmental and policy organisations and the attempts of scientists such as Anderson to reveal the "real clothes for the Emperor." Such attempts are made by similarly outspoken colleagues such as Alice Bows-Larkin [9], Professor of Climate Science and Energy Policy at University of Manchester, and Dr. James Hansen, Adjunct Professor of Earth and Environmental Sciences at Columbia University. In his 2012 TED talk, Why I Must Speak out About Climate Change, Hansen reveals his equivalent process to Anderson, of becoming an outspoken voice about the "real clothes" by stripping away the Emperor's clothes. Having spent two decades in comparative planetology looking up at the stars, and in planets such as Venus, Hansen's revelation of "Earth's energy imbalance and implications" was that the long-term trajectory of runaway climate change has the potential to lead to the Venus Syndrome: the eventual loss of the atmosphere on Earth, in an analogous manner to the process which occurred on Venus [10].

Hansen's initial research about the relationship between atmospheres on Venus and Earth was conducted at NASA between 1967-1980. Originally an atmospheric physicist, in 1980 he "resigned as principal investigator on our Venus experiment because a planet [Earth] changing before our eyes is more interesting and important" as "its changes will affect all of humanity" [11]. While director of the NASA Goddard Institute for Space Studies for over 30 years, he strayed outside of climate science and squarely into activating the domain between climate change and the politics and policy of energy [12]. The starting point to this was his congressional testimony to the US Senate Energy and Natural Resources Committee on 23 June 1988. This was the first high profile congressional session on climate change, and Hansen's unequivocal statements about the anthropogenic basis of the already changing climate were the first high profile scientific claims to this effect.

The following day his testimony was the subject of a front page article in The New York Times titled "Global Warming Has Begun, Expert Tells Senate" [13]. One article stands out in particular from the backlash where politicians and journalists attempted to re-clothe the Emperor rendered naked by Hansen. During the middle of summer the following year, science journalist Nicholas Wade published an op-ed also in The New York Times. Wade cited the 1989 summer being mild relative to the 1988 "heatwave" summer as vindication that Hansen was so mistaken about the planet warming such that "crying wolf on greenhouse warming will not work" [14]. This op-ed, titled Crying Wolf in the Greenhouse, foregrounded Aesop's fable about The Boy Who Cried Wolf to instill an instantly recognisable analogy for a false alarm, just as Anderson used Hans Christian's fable about The Emperor's New Clothes to instill an instantly recognisable analogy for a real alarm. In his op-ed response, Wolf in the Greenhouse, Hansen used the same metaphor to acknowledge "the danger of crying wolf too soon" due to how natural variability may anecdotally make climate change not appear to be manifest in the general 
public. Nevertheless, he closed his op-ed with the argument that "the time to cry wolf is here", due to the complexity arising when human values are factored into immutable biophysical properties:

A greater danger is to wait too long. The climate system has great inertia, so we have realized only part of the climate change that will be caused by gases we have added to the atmosphere. Add to this the inertia of the world's energy, economic and political systems, which will affect any plans to reduce greenhouse gas emissions [15].

Since this congressional testimony and its incipient backlash, Hansen's focus has been squarely on Earth's "energy, economic and political systems" although always seen with the insight of someone who has had his head in the sulphuric clouds of Venus.

The collective voice of such scientists form a corpus whose actions constitute a form of activism, by openly acknowledging that the clothing of the Emperor has long since transcended science, as it is now overly determined by the politics and policy of energy, which are, in turn, highly influenced by the domain of human values. This is apparent in Anderson's conclusion to his "Real Clothes for the Emperor" lecture. For a presentation brimming with statistics, graphs and data about the sheer scale of the planetary predicament, Anderson ends with a cautionary tale about his vision of "real hope" [1]. Before outlining his vision Anderson prefaces it with the alternative two "choices" for society. The first being to "continue the delusion that climate change can be addressed adequately through rhetoric, financial fine-tuning and piecemeal incrementalism" and the second being "to interpret such conclusions as a message of despair and futility" [1]. In contrast, the third and final "choice" for society is the "real clothes" for the Emperor:

real hope if it is to arise at all will do so from a bare assessment of the scale of the challenge that we now face and that's what I've tried to show here. This is where we are today. If we know where we are today we know what the scale of the problem is. If scientists keep underplaying it then we don't know it [1].

He then concludes the lecture with a quote "I always finish off with", by the philosopher and politician Roberto Mangabeira Unger: "at every level the greatest obstacle to transforming the world is that we lack the clarity and imagination to conceive that it could be different" [1]. Hands are raised by those who seek further clarity, before the event ends with everyone filing out into another unseasonably warm winter night which is $10^{\circ}$, exactly $2^{\circ}$ above the Bristol average for that time of year [16].

\section{Locating Hope between the Gutter and the Stars}

The transformative urgency advocated by Anderson and Hansen are not reverberating through graphics, statistics and data that activate the imagination or clarify the complex. The following sounds out such a reverberation, by framing the analogous challenges for two cultural fields that have recently emerged in direct response: energy humanities and the arts of energy. In contrast to the humanities and art more broadly, energy humanities and the arts of energy are pertinent to the perilous challenges of Anderson's "Real Clothes for the Emperor". Both take up at the point where Anderson signs off: by exploring how activating the imagination and clarifying the complex can mitigate obstacles to transforming the world. All three fields within science, humanities and art regarding energy are bound together by a common relationship within their respective domains: between the outspoken marginal and the orthodox mainstream. To broker a dialogue within each field between the outspoken and orthodox, and in so doing to precipitate the community-wide "ah ha!" realisation akin to exposing the Emperor as naked, the realm of cultural trope, idiom and metaphor are once again most apposite.

Oscar Wilde encapsulated this challenge within the broader domain of hope and despair, in his trope that "we are all in the gutter, but some of us are looking at the stars" [17]. The gutter, our immediate surrounding biophysical environment, is readily apparent as it is the detritus staring us in the face. It is also the point in public urban space that an object, such as detritus or a body, will congregate at as the gutter is the lowest physical plane that water gravitationally steers objects 
toward. Being within this guttural environment and excessively paying one's attention toward it hinders the ability to see a different order all together: the infinite space above, peppered by stars. This realm is outside: of the gutter, street, city, country, continent, and planet. It is also outside of here, now and our species. That starlight which so inspired Wilde was radiant energy travelling through interstellar space, the vast majority of which had originated before homo sapiens came into being.

Wilde held this out as a form of hope: for those able to look up at the stars from their stationary position in the gutter. In turn, such insight may ultimately manifest a context-contingent form of hope, born of seeing our gutter with our eyes and understanding anew, by turning our attention away from despairing in the detritus flowing along the gutter, toward a stellar aspiration that is still grounded in our guttural predicament. After all, there would not be enough heat to warm water to a liquid state for it to be able to travel down a gutter were it not for the radiant energy emitted by our local star, the sun. There is precious little in the known universe that is not touched by stellar energy, however disparaging the prospect of liquid water flowing along a gutter may seem.

This ability to broker the relationship between outspoken-orthodox and marginal-mainstream is evident in both Hans Christian and Wilde's work. While Hans Christian satirised the role of art in upholding the existing social order through the communal fear of not appearing to be an aficionado of the Emperor's invisible clothes, Wilde used his own art to attempt to turn the existing social order upside down, by rendering visible the hypocrisy, duplicity and corruption of the existing social order. Hans Christian and Wilde both actively laid bare the mainstream through the guise of the marginalised-whether of the child who first openly acknowledges the Emperor is naked, or of the artist whose plays, prose and poetry probed the relationship between art, aesthetics and power. Considered together, hope within such art practice is located in the transformative ability to precipitate a community-wide "ah ha!" realisation of real profundity, by clarifying the complex and activating the imagination.

The question then becomes how marginalised energy-fields within science, humanities and art may lay bare their respective mainstreams, to precipitate community "ah-ha" realisation in their respective fields. The thread connecting these diverse disciplines and fields is how this act of generating insight from sight — of the emperor as naked, the elephant in the room or the stars from the gutter-may diminish despair by allowing those to see our gutter with clarity and imagination anew. The hope that Wilde holds out is that if this transformational understanding were to be realised en masse, then this would precipitate a reappraisal of human values that are informed by an interplanetary and interstellar context. The hope that Anderson holds out is that if this transformational understanding were to be realised en masse, then this would precipitate necessary changes to energy policy. As the emerging energy humanities discourse is already attempting to precipitate this realisation throughout the humanities, the focus of this article is on addressing the gap in the literature on the arts of the energy, as informed by a critical reflection on the author's practice in this area.

\section{The Arts of Energy}

The term "energy" has highly specific usage in science and environmental policy: this is not the domain of metaphors, fables, and analogy, even through scientists such as Anderson, Broecker and Hansen use them to instill instantly recognisable imagery. In society, the term "energy" is generally re-animated in sociologist Jennifer Gabrys' sense, to refer to "any number of things, practices, and infrastructures" while being "scarcely visible itself as a concrete entity or resource" ([18], p. 2096). This polysemy is evident in just the first page of the 1.38 billion Google results in Australia for "energy" on 8 August 2015. The top three sponsored results were, in order: EnergyAustralia, a major fossil fueled based energy production company; Clean Energy Corporation Australia, a major renewable energy production company; and Healing Energy Sydney, a small scale local reiki therapist. The top news item appearing in the same search did not suffer from the same polysemy as it solely concerned energy regarding science and environmental policy: "Secret report reveals toxic legacy of coal gassification trials near SE Queensland town" [19]. 
The arts of energy currently exist with the same polysemy as these top Google results. In one sense, this is fitting, as "energy" has a plurality of meanings from "literal"/empirical, such as electromagnetic, chemical, kinetic, gravitational or physical energy, to "metaphorical" / subjective, such as spiritual, psychic or mental energy. However, for the arts of energy to engage with the more pertinent contexts of science and environmental policy, this polysemy needs to be clarified and focused on art vis-à-vis fossil fueled energy production and the cultural and biophysical effects stemming from such energy. While energy humanities initiatives have been established to bring humanities' perspectives to the deleterious biophysical effects of fossil fueled energy production, the arts of energy lack such focus. This is due to the absence of critical inquiry into such an arts of energy, combined with the predilection in dominant art practices toward the spectrum represented by the Google search result for Healing Energy Sydney - as representative of a broader constellation of spiritual, psychic or mental energy, rather than the contexts referred to by the search results of EnergyAustralia or the Clean Energy Corporation Australia. For art more broadly to engage with energy in ways apposite to the Anthropocene, closer dialogue is needed with the energy humanities and the physical sciences.

To date, this dialogue is far more amenable in energy humanities than the techno-scientific disciplines around energy. For instance, initiatives such as the new Nature Energy journal launched in January 2016 demonstrate how a pretense of academic disinteredness is rendered redundant in relation to the timeframes available to decarbonise global industrial societies. The editorial from the first volume lays out both the challenge and the disciplinary response in no uncertain terms:

It's clear that dealing with climate change calls for deep (and, likely, total) decarbonization of our energy system, which entails a fundamental transformation of our infrastructure. It also demands immediate and rapid action, as our window for avoiding the disastrous consequences of carbon emissions is ever shrinking ([20], p. 1).

The editors follow with what appears as an invitation toward the social sciences, and, to a lesser extent, the humanities:

No one discipline can truly claim to have all the answers to our energy challenges. What is needed is a multiplicity of voices-a combined effort from many disciplines all trying to understand how we can facilitate the energy transition but also all interacting with one another, sharing the benefits of their wisdom for the mutual good. Of course, this multitude speaks many different languages. Multi- and interdisciplinary studies—of which there are an ever-growing number-help here by playing an increasingly important role in removing the traditional boundaries between groups and broadening the conversation. By orienting ourselves around a subject, not a discipline, Nature Energy hopes to contribute too. We aim to be a home for the many different voices needed, publishing the best research and opinion on energy issues across the natural and social sciences ([20], p. 1).

To fulfill this vision of inclusivity, the journal, and the techno-scientific disciplines it addresses, would also need to stray outside of their normative boundaries toward the energy humanities, in a similar manner to Anderson and Hansen straying outside of climate science and into energy policy. To not do so risks perpetuating the lack of dialogue between the sciences, humanities and the arts around energy. However, a review of all Nature Energy articles at the time of publication found none beyond the techno-scientific disciplines or perspectives. As the reach out has thus far been dominated by energy humanities towards the physical sciences, and as energy humanities provide the most relevant framework for the arts of energy to be in dialogue with, the following outlines the energy humanities framework, including how scholars within this field frame the arts of energy.

The nascent field of "energy humanities" was created jointly in 2013 by the Petrocultures Research Cluster at the University of Alberta and the Center for Energy and Environmental Research in the Human Sciences (CEHNS) at Rice University. Both initiatives are at the centre of the dialogue emerging between energy and the humanities, on the basis that "today's energy and environmental dilemmas are 
fundamentally problems of ethics, habits, values, institutions, beliefs, and power-all traditional areas of expertise of the humanities and humanistic social sciences" [21]. CEHNS articulates a pluralistic vision in which "the expertise and leadership of" scientific and engineering research into energy is informed by the "need to better understand" the values, beliefs and institutional practice "that brought us to our present dilemmas if we are to hope for meaningful change." Collectively, they maintain that "it is thus imperative that we find ways to bring the expertise of the arts, humanities and social sciences more directly to bear on scientific research, technological planning and policy discussions" [22]. The recognition of this imperative is the subject of active investigation at other energy humanities initiatives, including: The Energy in the Humanities Group, University of Toronto; The Future of Energy Initiative, Harvard University; and in art: The Energies and Environments Research Group, University of New South Wales.

Of the rapidly increasing number of energy humanities conferences, Energy Cultures in the Age of the Anthropocene is broadly representative. Staged at the University of Iowa in March 2015, the conference aimed to "curate a humanistic effort to make sense of humans' relationship to energy and to come to terms with living in what many now consider to be the Age of the Anthropocene" [23]. In a similar vein, CENHS's twitter tagline, where one has 160 characters to articulate a mission statement, is "The Center for Energy and Environmental Research in the Human Sciences at Rice University assembles artists and scholars to think about our planet's future" [24].

CEHNS also investigates the distinct perspectives afforded by art as it may "offer critical insight into our ways of knowing and being in the world and help us to imagine alternate futures" [22]. Joseph Campana, an ecocritic at CENHS, describes the nebulous meanings in the arts of energy in relation to his survey of the 2013 Texas Contemporary Art Fair. Tellingly, he found a typology that did little to forestall how "it's so easy to drift off into metaphor" since "we use the term energy to describe many things." Staged in Houston, "a city saturated in energy money", Campana found two principal clusters for the arts of energy: referencing and/or representing "the consumption of energy" including that which "seemed to neutralize consumption and operation" but which did not do so in actuality; and work which he imputed with energetic qualities, such as "the way a painter leaves traces of effort in brushstrokes or the dynamism of line in a particularly well-composed photograph" [25].

To formulate a cogent response to the scale of the challenge outlined by Anderson and Hansen, Campana's two principal domains in the arts of energy-"pragmatic" energy production/consumption and the "poetic" representation of intrinsic energetic qualities-need to be brought into more sustained dialogue with one another. This is currently hindered by the nascent state of the literature on the arts of energy, with Campana's framing of the arts of energy being the first actual foray in the literature on the arts of energy. In response, the remainder of the article uses two case studies to formulate how such sustained dialogue may take place through actual practice. Such accounts are necessary as it is through critical reflection on such practice that the arts of energy may engage with the more pertinent contexts of science and environmental policy.

The following discussion concerns (re)materialising energy as both subject and modus operandi of artistic practice in both Campana's "pragmatic" and "poetic" domains of energy. How these two principal domains may be brought into dialogue with one another is discussed in terms of the simultaneously staged installations ISEA Bright Future and Facing Futures Free From Fear. The former uses a "pragmatic" evocation of the relationship between energy production/consumption and our planet's future while the latter uses a "poetic" evocation of intrinsic energetic qualities and our planet's future.

Thinking about our planet's future has a particular relationship to energy in the metaphor of a "bright future." Anderson and Hansen's challenge posed is that the means of producing the amount of incandescent brightness thus far have jeopardised future "brightness", in the sense of hope, which appears to diminish in inverse proportion to the amount of fossil fueled energy used to illuminate the planet. The centrality of "brightness" in relation to this future imaginary is encapsulated in how Anthropocene imagery revolves around nighttime satellite photographs of just how much of 
the planet is incandescently illuminated, such as the introductory photographs and film series on Anthropocene.info, the foremost general public information portal about the Anthropocene.

\section{ISEA Bright Future}

It is the evening of 14 June 2013. Another unseasonably warm winter night, seven months after Anderson's "Real Clothes for the Emperor" lecture, although on the other side of the globe, in Sydney, Australia. The temperature is $11^{\circ}$, exactly $3^{\circ}$ above the Sydney average for that time of year [26]. Five people are participating in ISEA Bright Future, an interactive installation conceived and directed by the author, and created in collaboration with a team of five artists and engineers. The participants are cycling atop five custom modified stationary e-bikes on training stands in a semi-circle. They are situated under a six-lane automobile bridge, on the sloping concrete banks which form a large gutter for the Parramatta River, one of the chief tributaries of Sydney Harbour. As each person peddles, they activate an array of LED lights that flashes at their cadence speed: 40 times per second when cycling at 40 RPM, 60 times per second when cycling at 60 RPM, and so on. Each full peddle rotation also activates a corresponding tuned percussion sound, creating an audiovisual array synchronised to their peddling speed. Each cyclist is thus generating their own rhythm and also a collective display caused by the sonic and visual interactions between the peddling speed of each cyclist.

An audience stands around the cyclists and their audiovisual array-listening and watching the patterns of light and sound dynamically fall into and out of synchronicity. They are there for Electric Nights, a festival of electronic art that forms part of the 2013 International Symposium of Electronic Art (ISEA). For its Parramatta setting, there are eight site-specific electronic artworks staged along the Parramatta River foreshore, while at the same time other festival sites in Sydney are exploring the labyrinthine relationships between art, science and technology.

The ISEA organisation, comprised of an academic conference integrated with an art festival, began in September 1988: three months after James Hansen's congressional testimony on climate change. It has since been held in a different country each year, growing to become the foremost annual electronic art festival. ISEA has been instrumental in the formation of Media Art, Electronic Art and Interactive Art-art forms that critically engage with relationships between art, science and technology. However, such critical engagement is rarely with the phenomenon of energy, despite the fact that such art can literally not be made, let alone presented, without silicon circuits pulsating with electrical energy overwhelming sourced from each host countries' power grid, and thus, overwhelming from fossil fuels.

Electrical energy flows through contemporary art in a similar manner to contemporary economies: in a critically unexamined and seemingly "immaterial" state, whereby the actual "material immaterialities of electronics and their networks...operate seemingly free of resources" [27]. This is not particular to ISEA as Gabrys finds this to be the case for energy more generally, which

it seems, animates any number of things, practices, and infrastructures, but is scarcely visible itself as a concrete entity or resource. If one were to try to identify where energy is located and what its salient features are, one might find it rather difficult to characterize in what ways energy is material ([18], p. 2095).

In response, Gabrys explores the ways in which energy can be materialised or rematerialised "as a material resource", which she has found to be "now a widespread approach and topic of discussion across social science research, environmental policy, and creative practice" [18] in art. ISEA Bright Future forms one such approach to (re)materialising energy as a "material resource."

ISEA Bright Future, commissioned by ISEA2013, (re)rematerialises energy in reference to the energy-intensive nature of ISEA itself, incorporating the organisation's name into the title of the work. The title is pronounced "I See A Bright Future" as the work explores how our planet's future will be dominated by how "brightness" is produced from electric-energy powered light. As the cyclists are co-participants, co-actuators and co-conductors of the behaviour of the work, the installation 
explores the role of cooperation and negotiation in forging such a future. It reflects back to the participants and surrounding audience about the extent to which they can choreograph their peddling in order to produce a harmonious audiovisual display, versus a chaotic display if their cadences are non-synchronous (see Figures 1-3). While doing so, the participants experience a direct sense of renewable energy production and embodied energy, as their physical peddling powers the entire installation via using the e-bikes they ride as power generators. Being bicycle-powered concerns participants physically feeling how much of their chemical energy is required to generate kinetic energy, and also demonstrating the ability for art about energy production to itself be "off the grid." In so doing, the work "articulate[s] an expanded array of practices for engaging with energy" as part of the field of creative practice Gabrys identified, which "suggest additional ways of performing the materialities of energy" through artworks "that variously harvest, scavenge, or generate 'alternative' modes of energy" ([18], p. 2096).

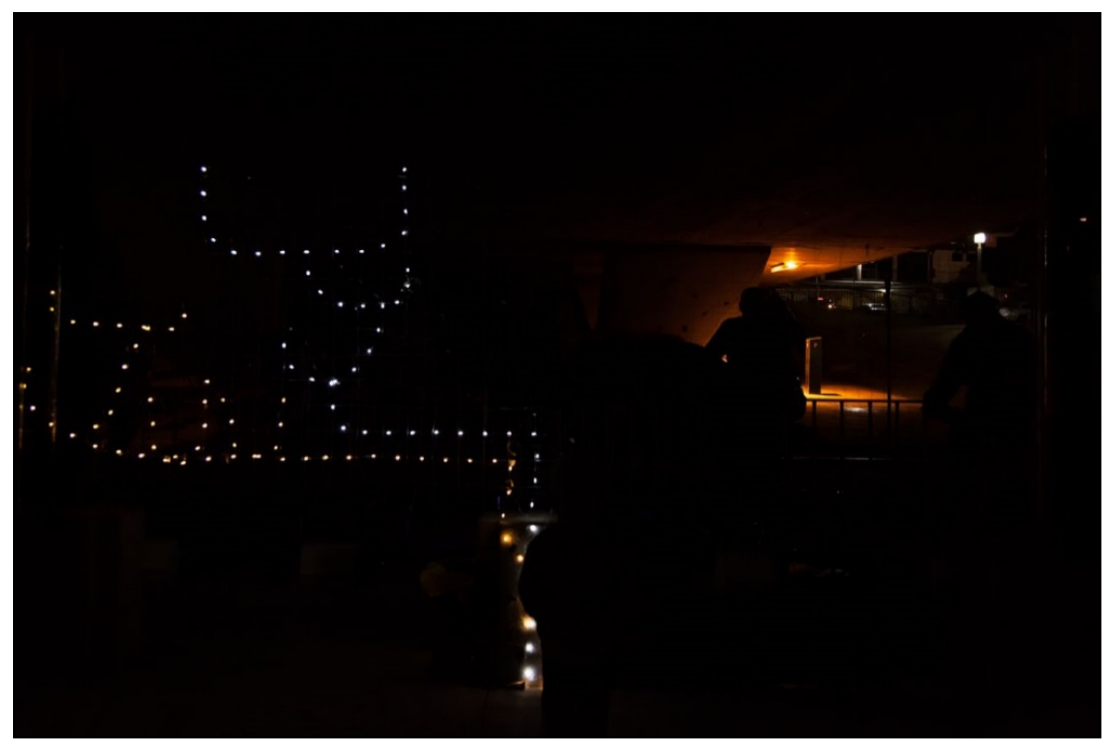

Figure 1. Participant \#1 and Participant \#2 in sync in ISEA Bright Future (2013).

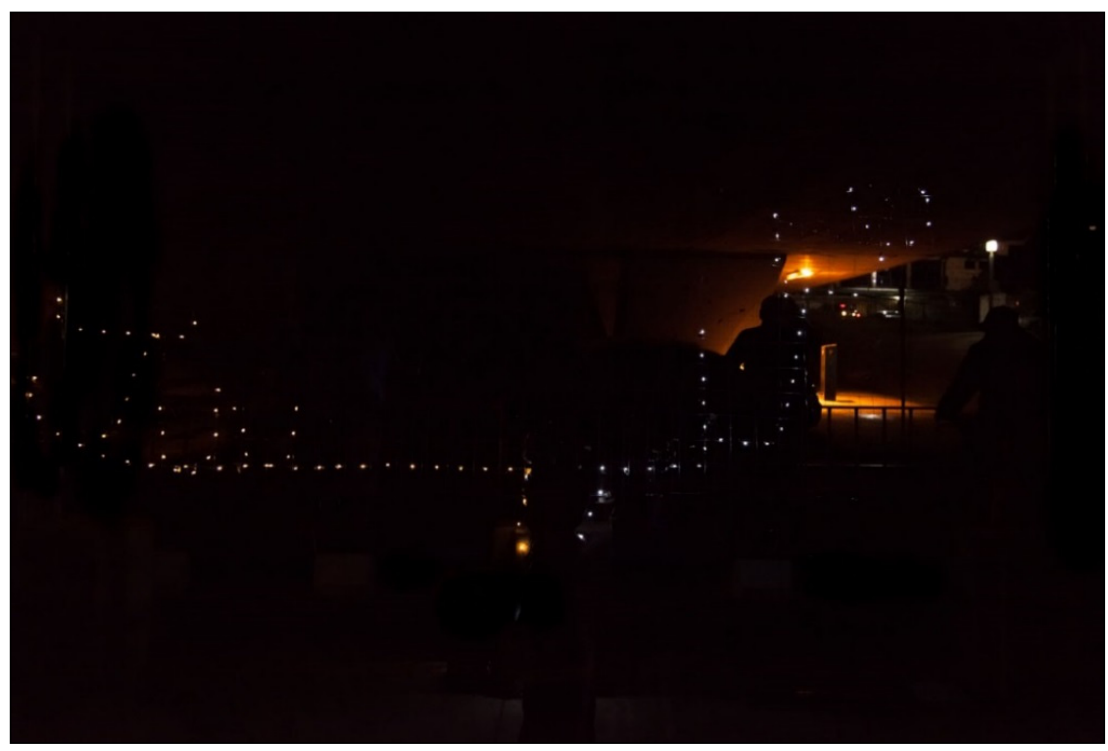

Figure 2. Participant \#1 and Participant \#5 in sync in ISEA Bright Future (2013). 


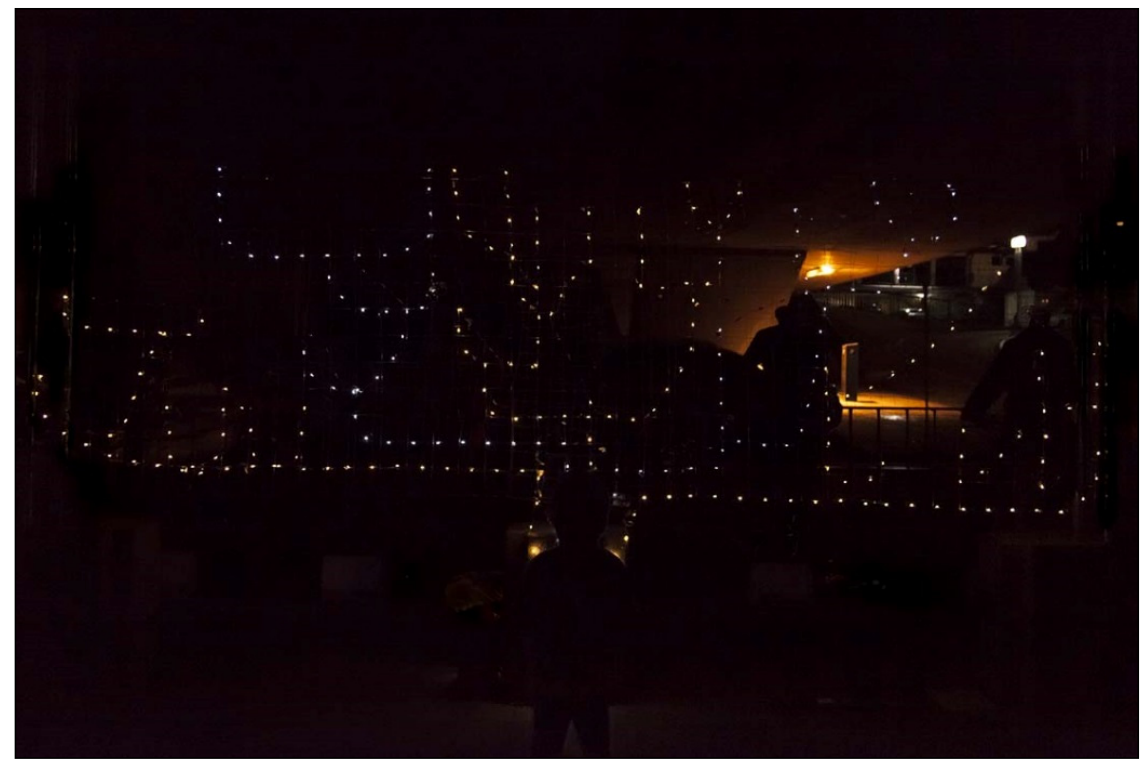

Figure 3. All five participants in sync in ISEA Bright Future (2013).

Bicycle-powered events have become increasingly common in Australian, North American and European community fairs, art festivals and local government awareness campaigns around energy. Such energy production systems literally lay bare the components required to convert human chemical energy into kinetic energy, by using ones legs as pistons to revolve bicycle peddles, and into electrical energy by bicycle generator systems. The BBC conducted a large-scale social experiment in such energy production in Human Power Station, a 2009 episode for their program Bang Goes The Theory [28]. The producers created a bicycle-powered generator system of 80 bicycles for 80 cyclists who powered an average UK house with an average sized UK family (of two parents and two teenage children) for one entire day. The family were instructed to go about their daily activities as per usual, and were not told that everything they were doing was being powered by the cyclists until after the experiment had been concluded. The results were illuminating for the cyclists-grimacing as they watched a large projection of the live family activities that they were powering - and for the family, who was afterward shown the video of how much physical energy expenditure was required from the cyclists in order for them to consume their daily energy usage.

This BBC experiment recalls the opening in Cultures of Energy: Power, Practices, Technologies, the 2013 ethnography about the cultural dimensions of energy usage. In the introduction, titled "Powerlines: Cultures of Energy in the Twenty First Century," and under the first heading, titled "Energy: Paradoxes, Predicaments, and Problems" the authors Sarah Strauss, Stephanie Rupp and Thomas Love argue that "our beliefs about energy shape how we use it" such that "our uses of energy simultaneously shape our cultural concepts of and beliefs about energy." Their reasoning, that "people perceive energy as invisible, omnipotent, and dangerous—or as desirable and indispensable, but perhaps unreliable" [29] is especially applicable to this BBC Human Power Station experiment, where the uninterrupted supply of energy that is central to global industrialised societies is subject to the contingencies of the cyclists' disbelief about how they can maintain sufficient kinetic energy output for the total sum of a day in the life of one family and one home.

In ISEA Bright Future, such communal energy is produced with an added layer of symbolism around biomimesis and bioluminescence: the flashing LED lights simulate how tropical fireflies collaboratively synchronise their flashing and the percussive soundscape simulates how insects such as crickets and cicadas collaboratively synchronise their calls. Both forms of synchronisation display emergent complexity from self-organising behaviour, where a multitude of organisms (which can be in the hundreds or even thousands of individual insects) are able to achieve spontaneous order by 
each coalescing their rhythms with their immediate neighbour. Collectively, this forms an overarching pattern of synchronised light/sound, yet without a hierarchy or centralised order. Biomimetically, the installation explores how audiences may spontaneously interact with one another and the work itself by choreographing the movement of their pedals. Before commencing, riders are instructed that their aim is to synchronize their peddling with their immediate neighbour to collectively synchronise the audiovisual array controlled by all cyclists.

In so doing, participants explore this same ability as fireflies, cicadas and crickets, in forming an overarching pattern of light/sound, yet with all the contingencies and variability of human behaviour, such as whether the different cyclists are determining their rhythm by monitoring the speed of their own flashing lights and/or percussive sounds, or whether they are monitoring their speed by comparing themselves to their neighbours, whether they are going too fast or too slow relative to one another and so on. The work is actuated by groups of people who know each other, and by other groups who do not, with participants drawn from the festival audience of children, parents, families and couples. Collectively, the installation reveals something of the social dynamics of our species: whether we seek to adjust our behaviour in cooperation with our neighbours, or whether we seek an individualistic mindset to behave independently of our neighbours, and, in so doing, how the marginal may become the mainstream, and vice versa. The laughter, cries of frustration and spontaneous bouts of congratulations between participants who are able to synchronise belie a deeper meaning in the work, arising in response to the existential challenge framed by Anderson and Hansen.

This existential challenge is also probed with reference to Wilde's model of taking inspiration from the stars: each time the participants illuminate the array of lights, they set of star-like map suspended over a literal gutter above a heavily polluted industrial river (Figure 3). The tropical fireflies that the participants are modelling do so likewise on riverbanks where they congregate and perform their synchronous flashing at night time. In the heavily urbanised environs of Sydney, the installation is also situated on a riverbank, although the offering is of a simulated artificial nature as a surrogate for what once was and is no longer.

Such simulations of nature already play out in the technology used in the installation itself. The bioluminescence of these tropical species of fireflies has been modeled in order to design and engineer next-generation LED lights which are orders of magnitude more energy-efficient [30,31]. However, the embodied energy underwriting the lighting system of each e-bike battery in the installation would require generating 500 hours of pedaling at 75 watts per hour just to generate the equivalent amount of energy used to make each battery [32]. In this context, ISEA Bright Future reinforces both Campana and Gabrys' respective surveys of the arts of energy. In line with Campana, while the work "seemed to neutralize consumption and operation" [25], it was not able to so in actuality when factoring in the embodied energy of the batteries. In line with Garbys, despite the literal energy production and the basis in embodied energy, the work materialises energy in such a way that it does "not necessarily involve making it visible or tangible or evident as a set of numerical readings or light levels." Rather, ISEA Bright Future centres on the "materialization or the mattering of energy" as it relates to "understanding what infrastructures, participants, and practices ensure its apparent immateriality" ([18], p. 2101). Nevertheless, the work offers a "pragmatic" evocation of energy production/consumption, in line with Campana's typology of the arts of energy.

\section{Facing Futures Free From Fear}

On the same night as ISEA Bright Future opened in Parramatta, its companion installation Facing Futures Free from Fear (FFFFF), also by the author, closed in Sydney College of the Arts gallery at the University of Sydney. The two installations were staged side by side, as they explored two complimentary ways of understanding energy: ISEA Bright Future concerned the physical production of kinetic energy and its transference into the radiant energy of light and sound, while FFFFF concerned the effects of the production and consumption of fossil fuelled energy in terms of the relationship between energy and heat. 
FFFFF was comprised of a portrait series of wall mounted photographic prints, a sculpture of nature photographs rising from the gallery floor to the ceiling, and a spoken voice sound collage that used two of the gallery walls as speaker membranes (see Figures 4-8). The wall portraits formed a vigil of the subjects encircling the wave created by the sculpture that parted the portrait subjects into the different sides of the gallery space. Unlike ISEA Bright Future, FFFFF offered a quiet, contemplative space, with the only sound being the collage of voices ruminating on matters past present and future.

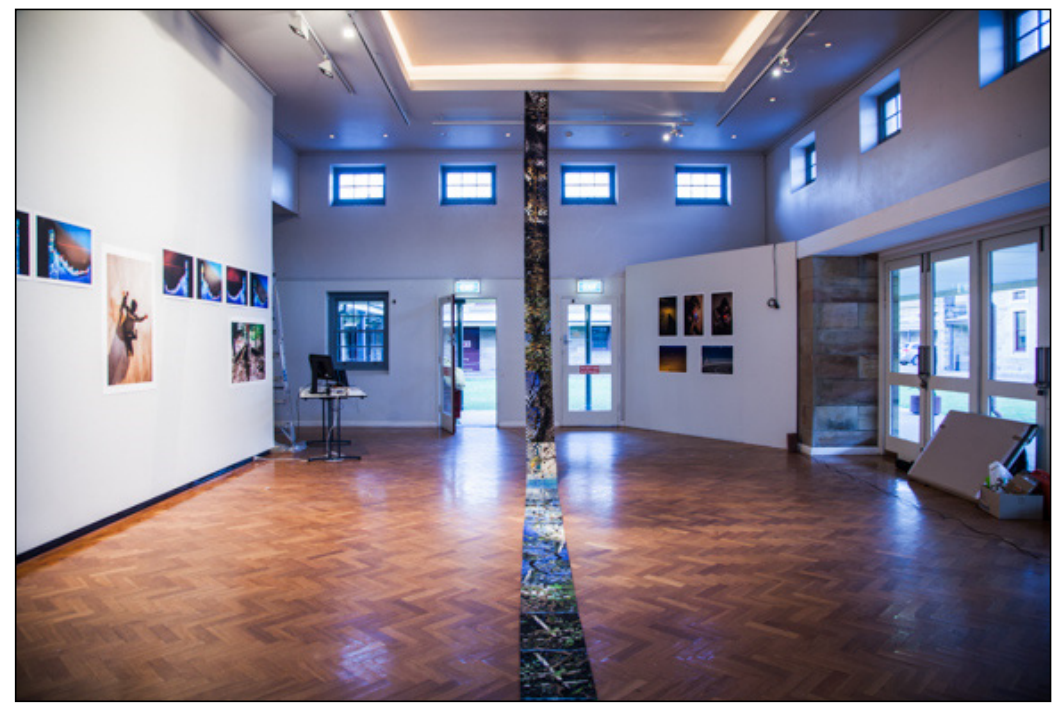

Figure 4. The Keeling (Over) Curve (years dot-thru-dash) (centre) in Facing Futures Free From Fear (2013).

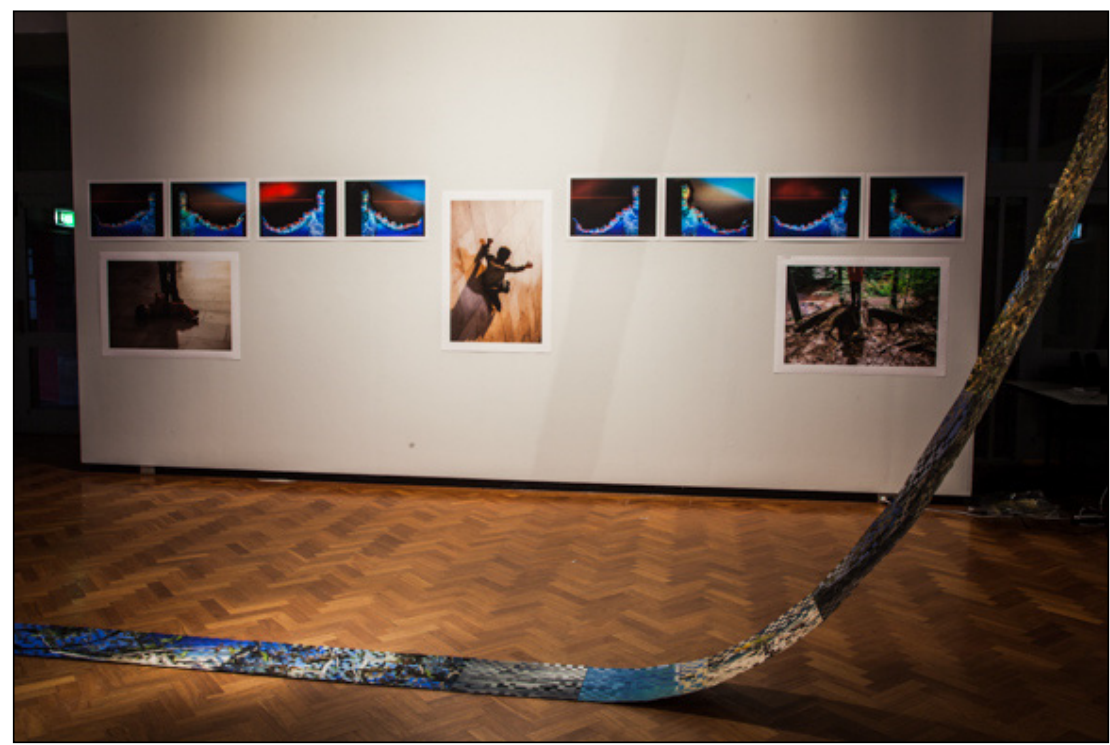

Figure 5. When I Was A Buoyant (centre) in Facing Futures Free From Fear (2013). 


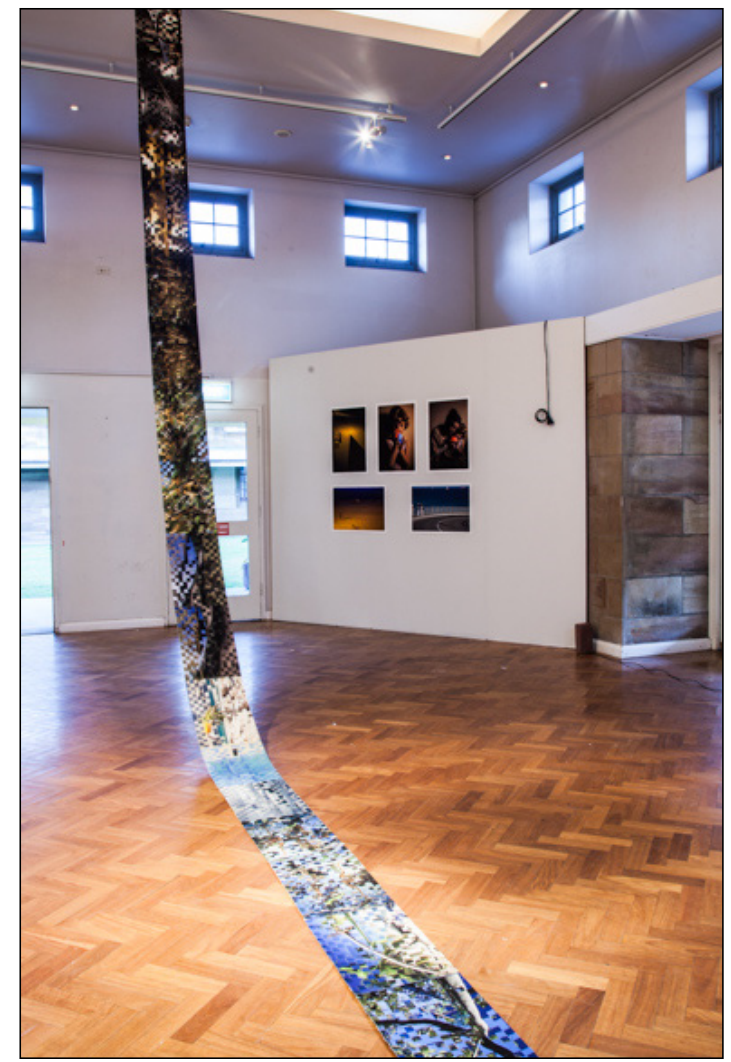

Figure 6. The Keeling (Over) Curve (years dot-thru-dash) in Facing Futures Free From Fear (2013).

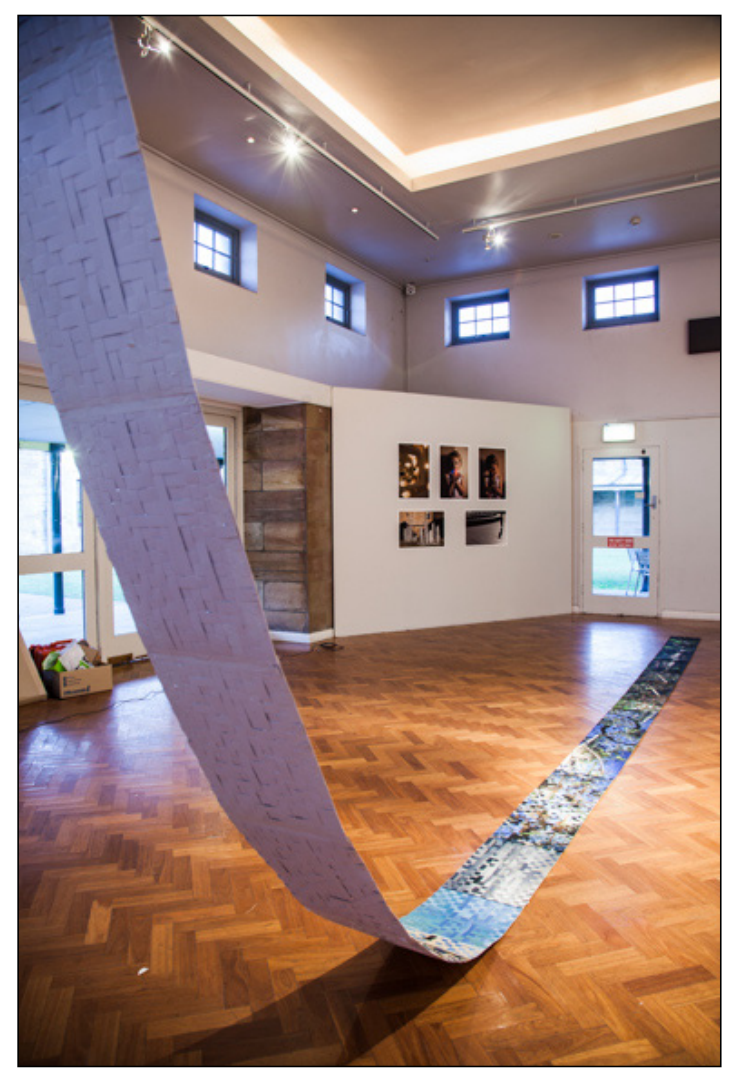

Figure 7. The Keeling (Over) Curve (years dot-thru-dash) in Facing Futures Free From Fear (2013). 


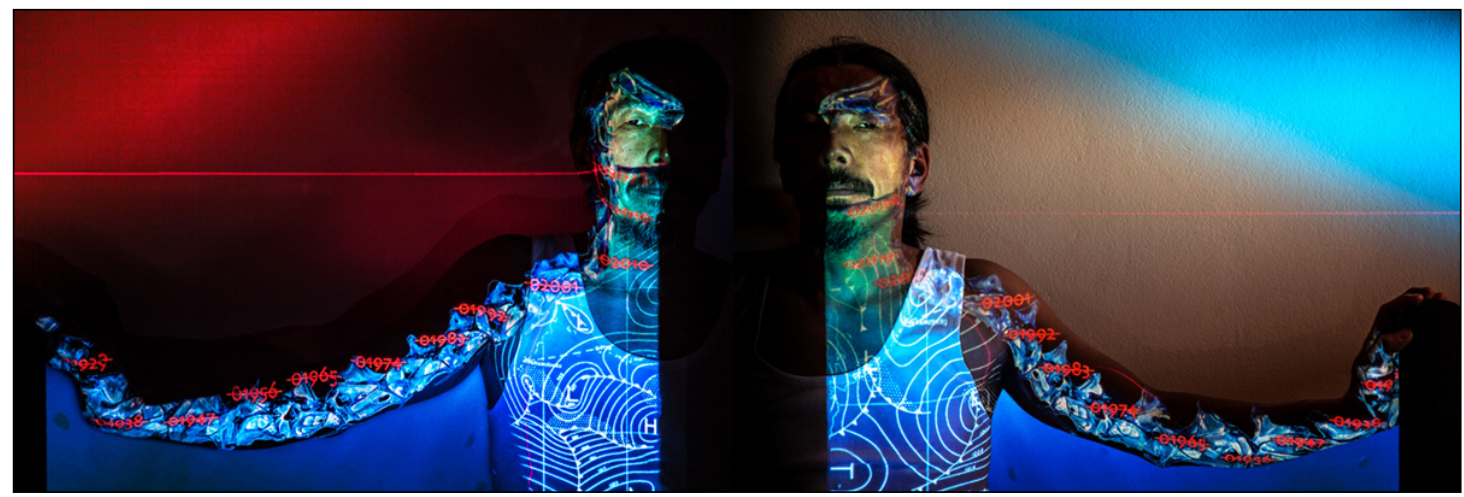

Figure 8. $>2$ degrees of separation <2028: Akira and <2 degrees of separation <2028: Akira from When I Was A Buoyant in Facing Futures Free From Fear (2013).

Together, the portraits, sculpture and sound collage ask: how do people face futures which are already and will increasingly be dominated by these unprecedented and incomparable consequences of climate change? How do people face such futures, free from fear, when the planet has already been anthropogenically changed to such an extent that Bill McKibben proposes renaming it "Eearth" [33]? In addition, how would one situate Anderson's "real hope" against the futures we are facing? Like Anderson and Hansen, FFFFF casts a modern interpretation of an old fable. Likewise, in the same manner that ISEA Bright Future forms a 3D evolutionary tree diagram, FFFFF (re)materialises energy by mapping Anderson and Hansen's graphs about the relationship between fossil fuelled energy production, climate change, and heat onto the human body and the gallery space itself. To illustrate how the installation weaves together these seemingly disparate strands, we must return to realm of fables from which FFFFF emanates.

The fable of King Canute and the sea goes that, in 1028, the King took his throne to the sea shore and sat in it in while he demonstrated he could command the tide to stop rising before it reached his chair. The laws of gravity with the orbit of moon and the attraction of the sun continued as they were. The tide rose. His body became soaked from having remained stationary. The King retreated, either into a newfound humility toward the forces of nature or in recognition of not possessing dominion over nature.

One millennium later, in 2028, asteroid 1997 XF11 will pass by, around 2.4 times the distance between the Earth and the moon. The announcement of this $1 \mathrm{~km}$-wide asteroid in March 1998 caused widespread alarm as the initial calculations predicated a remarkably higher likelihood of collision with the Earth than any others in the near future. More accurate calculations quickly followed, which asserted there was no likelihood of impact, but not before the initial trajectory stirred a public imagination in asteroid XF11 being "the one" that, on the balance of probabilities, this planet is long overdue to receive.

One month later, in April 1998, a highly influential article on climate change was published. This was the "hockey stick" argument, so called because the graph showed relatively rapid temperature increases since the beginning of the 20th Century, relative to the time since King Canute. The 1000 years represented by this line form a shape like a hockey stick: relatively straight for a long period of time, followed by an exponential curve upwards over a relatively small timescale (See Figure 9) [34]. 


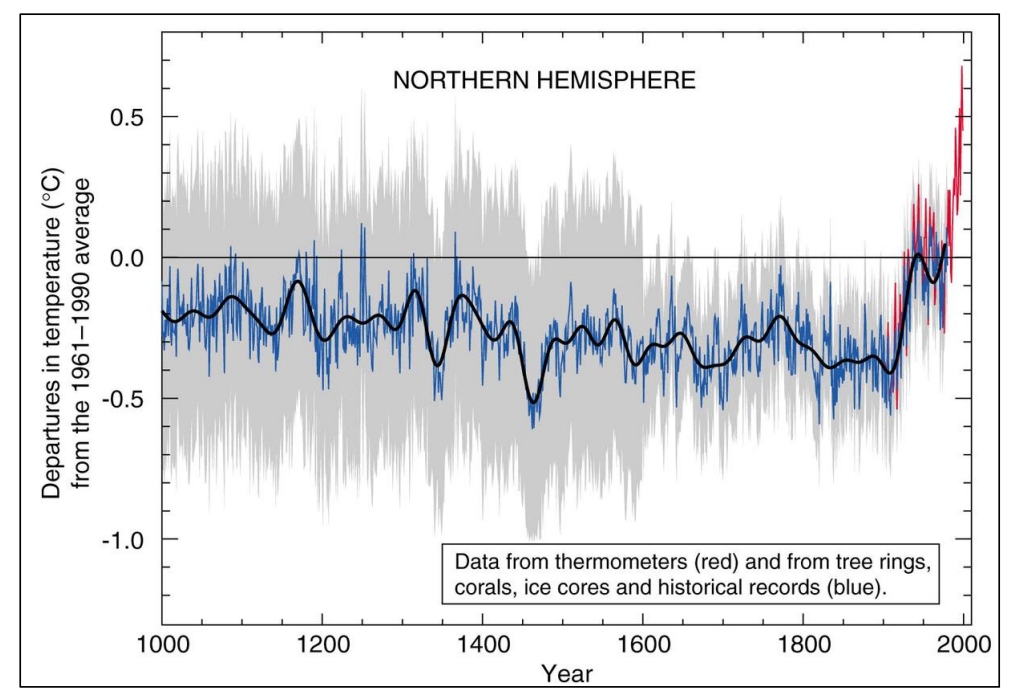

Figure 9. Michael Mann's “hockey stick graph.” Photograph: IPCC report, 1990.

The contours of the human arm and head share this shape. By stretching one's arm out flat, as in King Canute's posture toward the sea he sought to control, one looks back along a relatively straight line toward one's fingertips. What the eyes cannot see as clearly is the area of near-history: the approaching vertical rise beginning at the base of the neck and traveling up along the contours of the head. This near-history area is so close to our sensors that we appear to have a blind spot for it. Blind or not, it is self-evident that the head is significantly higher than the outstretched arm as it would otherwise not be possible to see so clearly down the length of the arm.

The diptych portraits are set in the midst of this period of near-history: the year 2028. They show different sea level heights in "best case" (less than $2^{\circ}$ temperature increase) and "worst case" (more than $2^{\circ}$ temperature increase) scenarios over the century leading up to 2028 (see Figure 8). The base rate of the portraits is February 2010, which is one nutation of the Earth before asteroid XF11 will pass by. It is within this single nutation that climate scientists are calling The Critical Decade [35]: the period in which the tipping point for limiting increases to less than $2^{\circ}$ will or will not be breached. The base rate is taken as the base of one's neck, as this is the universal height the sea comes up to on a buoyant body. It is us, any of us, treading water six summers ago in the sea. It is a situation of being in it up to our necks, with a narrowing margin remaining for the rate of rise to not outstrip the buoyancy of the body, like an ocean wave washing overhead while ones body remains stationary. In one scenario for the future, these life support systems are maintained: one's mouth and nose sit above the level of the sea (see Figure 8, right hand side). In the other, life ceases to be life as we know it (see Figure 8, left hand side).

Three thousand millenniums earlier, the concentration of $\mathrm{CO}_{2}$ in the atmosphere was 400 parts per million, with average temperatures $3-4^{\circ}$ warmer than today, and average sea levels $5-40$ metres higher than now [36]. In May 2013, for the first time in the intervening three thousand millenniums, the greenhouse gas emissions from fossil fueled energy production returned the atmosphere to 400 parts per million $\mathrm{CO}_{2}$.

That wave that has been recreated rises up from one's feet to well, five metres above head height, and with it all the detritus of the lifeforms it subsumes in its path (see Figures 6 and 7). That wave is a heatmap/timeline of the trajectory plotted by the Keeling Curve, which has kept continuous vigil of the increasingly increasing concentrations of $\mathrm{CO}_{2}$ in the atmosphere since 1958 (see Figure 10), and which scientists look to for the most authoritative barometer of what these critical numbers mean for how we face our futures. The wave is a tapestry of 1200 photographic strips of Northern Territory, Far North Queensland and Tongan littoral zones, where the areas at the front line meet the shifting 
shorelines. The strips were interwoven by hand into new constellations, like trees thrown around in a hurricane. Going from floor to ceiling, the single tapestry paints a picture from the darkest/coldest to lightest/hottest colour/temperature, as expanded by two new colours added by the Australian Bureau of Meteorology in January 2013 to compensate for the addition of $52^{\circ}$ and $54^{\circ}$ to the parameters for the contemporary climate (See Figure 11). Looked at from the base height of standing on the guttural ground, following the heat until it turns bright white requires tilting one's head backward to see it reach into the ceiling above. In line with Campana's typology of the arts of energy, the work offers a "poetic" representation of intrinsic energetic qualities; however, it does so in a manner suggestive of how the arts of energy may still manifest in non-electronic and non-interactive artforms, by (re)materialising energy through mapping that is faithful to the climate science.

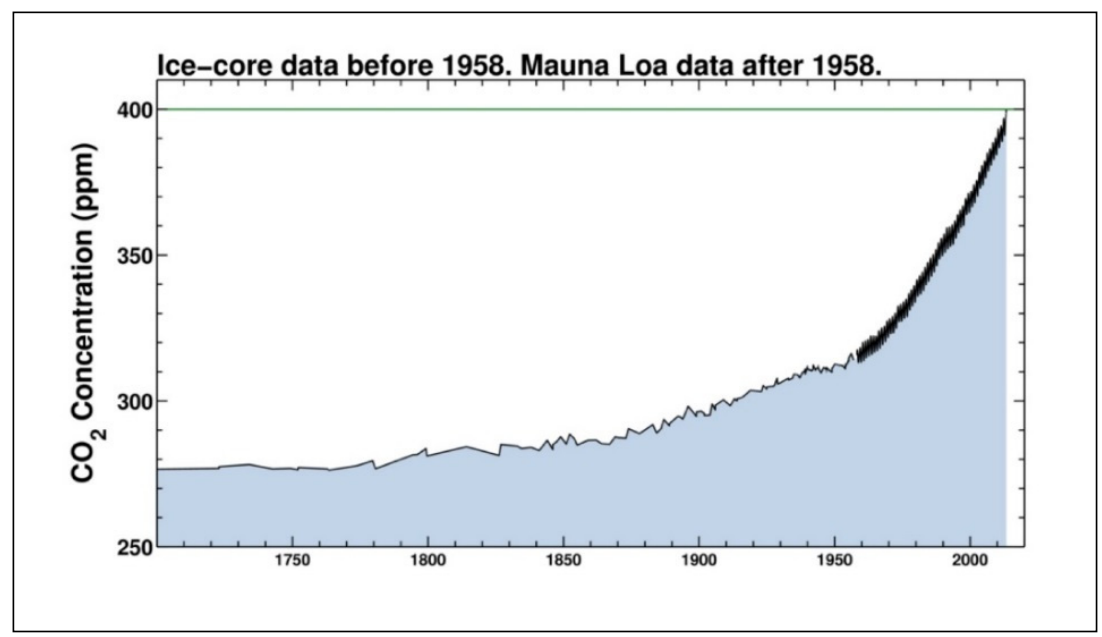

Figure 10. The Keeling Curve data, showing Earth reaching 400 parts per million of $\mathrm{CO}_{2}$ in 2013.

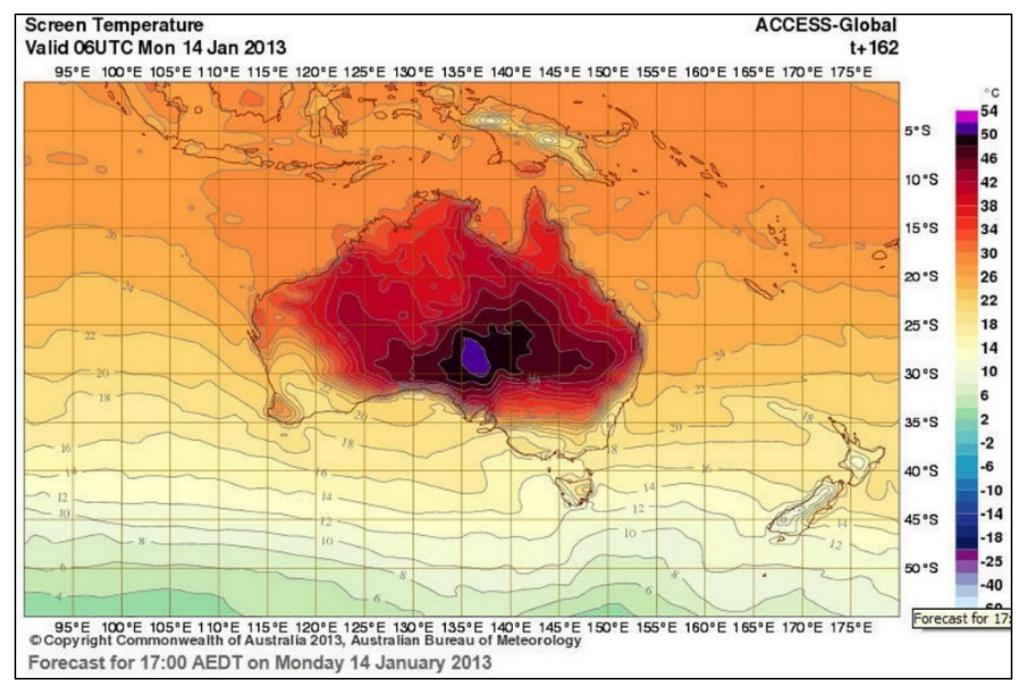

Figure 11. Heat map of Australia, showing the addition for the first time of new colours for $52^{\circ}$ and $54^{\circ}$, 14 January 2013, Australia Bureau of Meteorology.

\section{Conclusions: Follow the Heat}

On Anderson's advice, we are to follow Unger's adage that our lack of "clarity and imagination to conceive that it could be different" is our "greatest obstacle to transforming the world" [1]. The two case studies aim to illustrate how such imagination and clarity may be approached in both "pragmatic" 
and "poetic" domains within the arts of energy. For Wilde, hope in this context is to be able to look up at the stars from one's stationary position in the gutter so that this act of seeing may diminish despair by such insight allowing those to see our gutter with eyes and understanding anew. However, this act of seeing our gutter with eyes anew is not without peril: too deep a focus on the stars can render the gutter seemingly obsolete, which is contrary to the nature of the biophysical environment of the observer. Wilde proposed his model of understanding the human condition on Earth via its universal context in 1892, 28 years after the Greenhouse Effect in Earth's atmosphere was first experimentally proven, by UK physicist John Tyndall in 1864 [37], and four years before the first calculation of the anthropogenic influence of fossil fueled energy production on global climate was published, by Swedish physical chemist Svante Arrhenius in 1896.

Whatever hope Wilde may have had that his art would upheave the existing social order, he did not live to see. Imprisoned a year later in 1897, and dying destitute a further two down the track in 1900, his work still resonates with no lack of clarity or imagination to conceive that the world could be different. In 1998, a sculpture of Wilde by British artist Maggi Hambling was unveiled next to Trafalgar Square in London. Titled A Conversation With Oscar Wilde, the work is a sarcophagus like vertical marble slab that forms a public seat, with Wilde's head appearing through one end, as if engaging the seated in dialogue. At the opposite end, where his feat would be, facing upwards to the sky is inscribed his trope "we are all in the gutter, but some of us are looking at the stars." In February 2012, seven months before Anderson's "Real Clothes for the Emperor" presentation, British artist Michael Pinsky sought to project sea level rise 1000 years hence onto a series of nearby columns. Titled Plunge, each of the columns had a ring of blue LED lights suspended 28 metres above sea level, to depict this projected sea level in the year 3012. While the fable of King Cnut offers an understanding of human hubris in relation to sea level change 1000 years ago, Plunge, set 1000 years in the future, aims to relate us back to our contemporary predicament. In so doing, inscribing such speculative deep futures onto the fabric of high profile public space can appear to render our present as seemingly obsolete. Within the arts of energy, this can only further recalibrate hope against such speculate future contexts.

Such recalibration occurs as hope is always context-contingent. It is always by someone and for something (denoting a human someone to not impute such imaginings on to sentient non-human animals). Consequently, the meaning of hope is subject to recalibration against the scale of the challenges facing the future of life on Earth. In his article "Alone in the Void: Getting real about the tenuous and fragile nature of modern civilization," Paul Sutton argues that "the problems we face are often perceived as overwhelming. Hopelessness, helplessness, despair, and apathy are common reactions of those who learn of the myriad challenges we face" ([38], p. 187). If the hope is for the continuance of "modern civilization", or of the ongoing existence of a species, whether of coral, elephant, or of homo sapiens, then Anderson's notion of "real hope" is tenuous in Sutton's sense.

In light of this, hope can be recalibrated for a different order altogether, beyond the immediate future of anthropogenically induced mass species extinctions and toward what novel species may come to flourish by filling the voids left vacant in Earth's ecological niches. One means of such recalibrated hope is through thought experiments and speculative non-fiction. Alan Weisman's The World Without Us [39] and Jan Zalasiewicz's The Earth After Us [40] provide a framework for such recalibration. The former speculates on what life may manifest in a short-term disappearance of homo sapiens, and the latter on what may manifest 100 million years from now. They share an interest in forms of hope emerging from "a damaged planet" of "blasted landscapes" [41], which could be a planet where bacteria, extremophiles and fungi once again reign supreme, or of other forms of biodiversity inconceivable to our species today.

Such recalibrations of hope build upon envisioning environmental scenarios in the context of facing futures in their plurality rather than "The Future" [42]. In the same context, Mike Hulme offers a counterpoint notion of hope in his apologetic about "Climate Change and Virtue", where individual or collective frailty is not mutually exclusive to his vision: 
Hope captures the human relationship with the future. If human knowledge is inescapably bound up with the notion of faith, then our relationship with the future is written in the language of hope. Of course we may see the general future-or our own personal future-as hopeful or hopeless, but the virtue of hope captures something about the unquenchable human desire for something better. Hope, then, is a virtue which needs nourishing, in both public and personal settings ([43], p. 306).

To tether such hope operating at the scale of deep time and deep space in the actual here and now, I close with Anderson's "tenuous hope" for contemporary global energy policy reform and enforcement in his article "Climate Change Going Beyond Dangerous: Brutal Numbers and Tenuous Hope":

The future is almost beyond what we can imagine, what we have ever seen before. Therefore, our role now is to think differently, to achieve greater clarity, to foster a greater imagination and to no longer keep saying that it is impossible. We must make the impossible possible. There is real hope, but that hope reduces significantly each day ([44], p. 39).

Being "almost beyond what we can imagine", the role that the arts of energy may play is in bringing this poetic-pragmatic imagination within reach, to precipitate the community-wide "ah ha!" realisation of the Emperor's nakedness, the elephant's anger and the visibility of the stars from the gutter.

Acknowledgments: I am indebted to my two anonymous reviewers for encouraging me to expand and refine my treatment of several important issues.

Conflicts of Interest: The author declares no conflict of interest.

\section{References and Notes}

1. Kevin Anderson. "Real clothes for the Emperor: Facing the Challenges of Climate Change." Paper presented at the Cabot Institute, University of Bristol, Bristol, UK, 6 November 2012. Available online: http:/ / www. bristol.ac.uk/cabot/events/2012/194.html (accessed on 13 December 2015).

2. Hans Christian Andersen. “The Emperor's New Clothes." In Fairy Tales Told for Children. Copenhagen: C.A. Reitzel, 1837.

3. Kevin Anderson, and Alice Bows. "Beyond 'dangerous' Climate Change: Emission Scenarios for a New World." Philosophical Transactions of the Royal Society of London A: Mathematical, Physical and Engineering Sciences 369 (2010): 20-44. [CrossRef] [PubMed]

4. Wallace Broecker, quoted in Eugene Linden. The Winds of Change: Climate, Weather, and the Destruction of Civilizations. New York: Simon and Schuster, 2006, vol. 3.

5. Eviatar Zerubavel. The Elephant in the Room: Silence and Denial in Everyday Life. London: Oxford University Press, 2007.

6. Will Steffen, Wendy Broadgate, Lisa Deutsch, Owen Gaffney, and Cornelia Ludwig. "The Trajectory of the Anthropocene: The Great Acceleration." The Anthropocene Review 2 (2015): 81-98. [CrossRef]

7. Beth Shapiro. How to Clone a Mammoth: The Science of De-Extinction. Princeton: Princeton University Press, 2015.

8. Jens-Christian Svenning, Pil B. M. Pedersen, C. Josh Donlan, Rasmus Ejrnaes, Søren Faurby, Mauro Galetti, Dennis M. Hansen, Brody Sandela, Christopher J. Sandomg, John W. Terborgh, and et al. "Science for a Wilder Anthropocene: Synthesis and Future Directions for Trophic Rewilding Research." Proceedings of the National Academy of Sciences USA 113 (2016): 898-906. [CrossRef] [PubMed]

9. Kevin Anderson, and Alice Bows. "Reframing the climate change challenge in light of post-2000 emission trends." Philosophical Transactions of the Royal Society of London A: Mathematical, Physical and Engineering Sciences 366 (2008): 3863-82. [CrossRef] [PubMed]

10. James Hansen. "Climate Urgency." Simulation \& Gaming 44 (2013): 232-43. [CrossRef]

11. James Hansen. "Why I must speak out about climate change." Paper presented at the TED Conference, Longbeach, CA, USA, 28 February 2012. Available online: https://www.ted.com/talks/james_hansen_ why_i_must_speak_out_about_climate_change/transcript?language=en (accessed on 13 December 2015). 
12. James Hansen, Makiko Sato, Pushker Kharecha, David Beerling, Robert Berner, Valerie Masson-Delmotte, Mark Pagani, Maureen Raymo, Dana L. Royer, and James C. Zachos. “Target Atmospheric $\mathrm{CO}_{2}$ : Where Should Humanity Aim?" The Open Atmospheric Science Journal 2 (2008): 217-31. [CrossRef]

13. Philip Shabecoff. “Global Warming Has Begun, Expert Tells Senate." The New York Times, 24 June 1988. Available online: http://www.nytimes.com/1988/06/24/us/global-warming-has-begun-expert-tellssenate.html (accessed on 13 December 2015).

14. Nicholas Wade. "Crying Wolf in the Greenhouse." The New York Times, 3 July 1989. Available online: http: / /www.nytimes.com/1989/07/03/opinion/the-editorial-notebook-crying-wolf-in-the-greenhouse.html (accessed on 13 December 2015).

15. James Hansen. "Wolf in the Greenhouse." The New York Times, 1 August $1989 . \quad$ Available online: http:/ / www.nytimes.com/1989/08/01/opinion/l-let-s-not-count-on-the-earth-to-heal-itself-wolfin-the-greenhouse-972189.html (accessed on 13 December 2015).

16. Weather Underground. "Bristol Airport, Day and Night Temperature Records for 6 November 2012." Available online: http://www.wunderground.com/history/airport/EGGD/2012/11/6/DailyHistory. html?req_city=Bristol\&req_state=\&req_statename=United+Kingdom\&reqdb.zip $=00000 \&$ reqdb.magic $=3 \&$ reqdb.wmo=03724 (accessed on 13 December 2015).

17. Oscar Wilde. Lady Windermere's Fan. London: Nick Hern Books, 1892, p. 2005.

18. Jennifer Gabrys. "A Cosmopolitics of Energy: Diverging Materialities and Hesitating Practices." Environment and Planning A 46 (2014): 2095-109. [CrossRef]

19. Mark Solomons, and Mark Willacy. "Secret Report Reveals Toxic Legacy of Coal Gasification Trials near SE Queensland Town." ABC News, 10 August 2015. Available online: http:/ /www.abc.net.au/news/2015-0810/linc-energy-secret-report-reveals-toxic-chemical-risk/6681740 (accessed on 13 December 2015).

20. Nicky Dean. "A world in transition." Nature Energy 1 (2016): article 15026.

21. Dominic Boyer, and Imre Szeman. "The rise of energy humanities: Breaking the impasse." University Affairs, 12 February 2014. Available online: http://www.universityaffairs.ca/opinion/in-my-opinion/the-rise-ofenergy-humanities/ (accessed on 13 December 2015).

22. The Center for Energy and Environmental Research in the Human Sciences, Rice University. "What is CENHS?" Available online: http://culturesofenergy.com/about/ (accessed on 13 December 2015).

23. Obermann Center for Advanced Studies. "Energy Cultures in the Age of the Anthropocene." Available online: http:/ / obermann.uiowa.edu/programs/humanities-symposium/energy-cultures-ageanthropocene (accessed on 13 December 2015).

24. The Center for Energy and Environmental Research in the Human Sciences, Rice University. Available online: https:/ / twitter.com/cenhs (accessed on 13 December 2015).

25. Joseph Campana. “'What do you mean by energy?' Texas Contemporary Art Fair.” Alternate Current. Available online: http:/ / alternatecurrents.blogs.rice.edu/tag/energy/ (accessed on 13 December 2015).

26. Weather Underground. "Sydney Airport, day and night temperature records for 14 June 2013." Available online: http://www.wunderground.com/history/airport/YSSY/2013/6/14/DailyHistory.html?req_ city $=$ Sydney\&req_state $=\&$ req_statename $=\mathrm{New}+\mathrm{South}+$ Wales\&reqdb.zip $=00000 \&$ reqdb.magic $=1 \&$ reqdb. wmo=94767 (accessed on 13 December 2015).

27. Jennifer Gabrys. "Powering the Digital: From Energy Ecologies to Electronic Environmentalism." In Media and the Ecological Crisis. Edited by Richard Maxwell, Jon Raundalen and Nina Lager Vestberg. New York: Routledge, 2014, p. 5.

28. BBC. "Bang Goes the Theory: Human Power Station." 3 December 2009. Available online: http://www.bbc. co.uk/programmes/b00p8469 (accessed on 13 December 2015).

29. Sarah Strauss, Stephanie Rupp, and Thomas F. Love. "Powerlines: Cultures of Energy in the Twenty First Century." In Cultures of Energy: Power, Practices, Technologies. Edited by Sarah Strauss, Stephanie Rupp and Thomas F. Love. Walnut Creek: Left Coast Press, 2013, p. 10.

30. Annick Bay, Peter Cloetens, Heikki Suhonen, and Jean Pol Vigneron. "Improved Light Extraction in the Bioluminescent Lantern of a Photuris Firefly (Lampyridae)." Optics Express 21 (2013): 764-80. [CrossRef] [PubMed]

31. Jae-Jun Kim, Youngseop Lee, Ha Gon Kim, Ki-Ju Choi, Hee-Seok Kweon, Seongchong Park, and Ki-Hun Jeong. "Biologically Inspired LED Lens from Cuticular Nanostructures of Firefly Lantern." Proceedings of the National Academy of Sciences USA 109 (2012): 18674-78. [CrossRef] [PubMed] 
32. Kris De Decker. “Bike Powered Electricity Generators are not Sustainable.” Low-Tech Magazine, 1 June 2011. Available online: http:/ /www.resilience.org/stories/2011-06-01/bike-powered-electricity-generators-arenot-sustainable (accessed on 27 December 2015).

33. Bill McKibben. Eaarth: Making a Life on a Tough New Planet. New York: St. Martin's Griffin, 2011.

34. Michael Mann, Raymond Bradley, and Malcolm Hughes. "Northern hemisphere temperatures during the past millennium: Inferences, uncertainties, and limitations." Geophysical Research Letters 26 (1999): 759-62. [CrossRef]

35. Will Steffen, and Lesley Hughes. The Critical Decade 2013: Climate Change Science, Risks and Response. Canberra: Climate Commission Secretariat, 2013.

36. Aradhna Tripati, Christopher Roberts, and Robert Eagle. "Coupling of $\mathrm{CO}_{2}$ and Ice Sheet Stability over Major Climate Transitions of the Last 20 Million Years." Science 326 (2009): 1394-97. [CrossRef] [PubMed]

37. This is the person after which the Tyndall Centre for Climate Change Research is named, where Kevin Anderson and Alice Bows-Larkin are based.

38. Paul Sutton. "Alone in the Void: Getting Real about the Tenuous and Fragile Nature of Modern Civilization." Humanities 1 (2012): 178-91. [CrossRef]

39. Alan Weisman. The World without Us. New York: St. Martin's Press, 2007.

40. Jan Zalasiewicz. The Earth after Us: What Legacy will Humans Leave in the Rocks? Oxford: Oxford University Press, 2008.

41. Anna Tsing. "Blasted landscapes (and the gentle arts of mushroom picking)." In The Multispecies Salon. Edited by Eben Kirksey. Durham: Duke University Press, 2014, pp. 87-110.

42. Josh Wodak, and Timothy Neale. "A Critical Review of the Application of Environmental Scenario Exercises." Futures 73 (2015): 176-86. [CrossRef]

43. Mike Hulme. "Climate Change and Virtue: An Apologetic." Humanities 3 (2014): 299-312. [CrossRef]

44. Kevin Anderson. "Climate change going beyond dangerous: Brutal numbers and tenuous hope." Development Dialogue 61 (2012): 16-39.

(C) 2016 by the author; licensee MDPI, Basel, Switzerland. This article is an open access article distributed under the terms and conditions of the Creative Commons Attribution (CC-BY) license (http://creativecommons.org/licenses/by/4.0/). 